\title{
Efficacy of PET-CT in the Diagnosis and Treatment of Recurrence After Esophageal Cancer Surgery
}

\author{
MICHIHIRO KUDOU, ATSUSHI SHIOZAKI, HITOSHI FUJIWARA, HIROTAKA KONISHI, TOMOHIRO ARITA, \\ TOSHIYUKI KOSUGA, RYO MORIMURA, YASUTOSHI MURAYAMA, SHUHEI KOMATSU, YOSHIAKI KURIU, \\ HISASHI IKOMA, MASAYOSHI NAKANISHI, DAISUKE ICHIKAWA, KAZUMA OKAMOTO and EIGO OTSUJI
}

Division of Digestive Surgery, Department of Surgery,

Kyoto Prefectural University of Medicine, Kyoto, Japan

\begin{abstract}
Aim The present study aimed to retrospectively investigate the utility of positron-emission tomography with 2-deoxy-2-[fluorine-18]fluoro-D-glucose integrated with computed tomography (PET-CT) in regular follow-ups after esophageal cancer surgery. Patients and Methods: Clinical outcomes were retrospectively analyzed for 61 patients who were diagnosed with postoperative recurrence using PET-CT. Results: A univariate analysis revealed that single recurrence, a low cytokeratin 19 fragment (CYFRA) value, chemoradiotherapy against recurrence, and recurrence over 6 months after surgery were significant prognostic factors. A low CYFRA level and single recurrence tended to be good prognostic factors in the multivariate analysis. The prognosis of cases with single recurrent tumor of size less than $10 \mathrm{~mm}$ was significantly better than those with tumors of $10 \mathrm{~mm}$ or more. PET-CT revealed small recurrent tumors, and contributed to the early detection of recurrence outside the body trunk. Conclusion: PET-CT contributes to the detection of single small recurrent tumors and those outside the body trunk. This follow-up method using PET-CT should be considered for patients after esophageal cancer surgery.
\end{abstract}

Esophageal cancer (EC) is the eighth most common cancer worldwide, with an estimated 456,000 new cases in 2012 (3.2\% of all cases), and the sixth most common cause of death from cancer, with an estimated 400,000 deaths (4.9\% of all deaths)

This article is freely accessible online.

Correspondence to: Assistant Professor, Dr. Atsushi Shiozaki, Division of Digestive Surgery, Department of Surgery, Kyoto Prefectural University of Medicine, 465 Kajii-cho, Kamigyo-ku, Kyoto 602-8566, Japan. Tel: +81 752515527, Fax: +81 752515522, e-mail: shiozaki@koto.kpu-m.ac.jp

Key Words: Esophageal cancer, PET-CT, post-operative follow-up.
(1). Although several diagnostic modalities and multimodal therapies have been developed in recent years, the prognosis of patients with EC remains poor even when curative surgery is performed. Postoperative recurrence occurs in $78 \%$ of patients who undergo curative surgery for EC $(2,3)$. Recurrence of EC is regarded as a grave prognostic sign after curative surgery, with most patients dying due to the progression of their cancer. However, a few patients with postoperative recurrence have achieved long-term survival $(4,5)$. The development of more effective therapies or examinations is presumed to have improved the clinical outcomes of patients with recurrent EC. In order to achieve further improvements in the prognosis of these patients, the characteristics of recurrent cases that survive long-term, and prognostic factors for recurrent EC need to be elucidated in more detail.

Positron-emission tomography with 2-deoxy-2-[fluorine18]fluoro-D-glucose, an analog of glucose, integrated with computed tomography (PET-CT) is a functional imaging technique based on increased glucose uptake and glycolysis by cancer cells. In Japan, EC was approved as an indication for the use of PET-CT under health insurance coverage in April 2006. PET-CT is now widely used and provides a sensitive and specific examination for the staging or diagnosis of recurrent lesions in various lips of cancer (6-8). Furthermore, a previous study showed that PET-CT was useful for the early detection of recurrence after esophagostomy, and contributed to a good prognosis through early detection of single recurrent tumors (5). Although the utility of PET-CT in EC has been reported, an appropriate method for applying PET-CT to follow-up after curative surgery for EC has not yet been established. In order to provide EC patients the best medical care, it is necessary to clarify the utility of PET-CT in postoperative follow-up.

PET-CT was implemented at our Institution in March 2007. We have been conducting imaging observations for regular follow-up of patients who underwent curative surgery for EC in our Division using PET-CT since January 2008. The present study aimed to retrospectively investigate the 
utility of PET-CT in regular follow-up of patients after curative surgery for EC.

\section{Patients and Methods}

Patients. Between January 2008 and December 2014, 235 patients underwent curative surgery for squamous cell carcinoma of the esophagus the at the Division of Digestive Surgery of Kyoto Prefectural University of Medicine. Patients who underwent preoperative therapies, e.g. neoadjuvant chemoradiotherapy (CRT) or preoperative definitive CRT, which are not standard therapies by the Japanese EC guidelines (9), or whose tumor invaded surrounding tissues (pT4) were excluded. Recurrence was detected in 63 out of the 198 remaining patients. Follow-up was not possible in two out of the 63 patients, and thus, they were excluded. We retrospectively analyzed data for the remaining 61 patients. The clinical and pathological classifications of EC were diagnosed based on the Japan Classification System by physicians and the pathologist at our hospital (10).

Surgery. Transthoracic esophagectomy was performed on 36 out of 61 patients $(59.0 \%)$ whose data were analyzed in the present study. Video-assisted thoracic esophagostomy was performed on 14 of these patients $(22.9 \%)$. Eleven patients (18.0\%) underwent esophagectomy with a laparoscopic transhiatal approach. All patients underwent two-field (thoracic and abdominal) or three-field (cervical, thoracic, and abdominal) lymphadenectomy.

PET-CT. ${ }^{18} \mathrm{~F}-\mathrm{FDG}$ was purchased from Nihon Medi-Physics (Tokyo, Japan). Patients were instructed to fast for at least $4 \mathrm{~h}$ before PETCT imaging. Whole-body PET-CT images were acquired $1 \mathrm{~h}$ after the intravenous injection of $185 \mathrm{MBq}$ of ${ }^{18} \mathrm{~F}-\mathrm{FDG}$, and emission scans were obtained from the head to thigh for $120 \mathrm{~s} / \mathrm{bed}$ per field of view with the use of an integrated PET/CT system with 16 slice CT (Aquiduo, Toshiba, Tokyo, Japan). Normal CT scans were performed with the use of 64 or 128 helical CT. The diameters of tumors were evaluated based on RECIST 1.1 (11).

Postoperative follow-up. An imaging examination for the postoperative follow-up was performed using whole-body PET-CT, performed every 4-6 months after curative surgery depending on the pathological findings of the resected specimens. The tumor markers squamous cell carcinoma antigen (SCC) and cytokeratin 19 fragment (CYFRA) were assayed every 3 months after surgery. Upper gastrointestinal endoscopy was performed at least once every year after surgery. Seven patients were diagnosed with postoperative recurrence based on CT findings; six of these patients intentionally underwent $\mathrm{CT}$ for a detailed examination of symptoms that indicated recurrence, e.g. swelling of the neck lymph nodes detected during a physical examination, the remaining patient underwent CT for a detailed examination of postoperative complications and recurrence was incidentally detected.

Response evaluation of treatments against recurrence. A response evaluation of treatments against recurrence was also performed 3 months after the end of treatment using PET-CT. Although treatment responses were basically assessed by measuring tumor diameters in plain-CT images based on RECIST 1.1, the disappearance of the abnormal uptake of FDG in recurrent regions was added to the requirements for a complete response (CR). Patients who achieved $\mathrm{CR}$ were regularly followed-up postoperatively using PET-CT.
Statistical analysis. Survival curves were estimated by the KaplanMeier method, and differences in survival were examined using the log-rank test. Cox's proportional hazard model was used to identify independent prognostic factors. $p$-Values of less than 0.05 were regarded as significant.

\section{Results}

Patient characteristics. The characteristics of 61 patients with squamous cell carcinoma of the esophagus are summarized in Table I. The median follow-up time was 705 days (range=164-2,759 days). Fifty-five patients received neoadjuvant chemotherapy with 5-fluorouracil and cisplatin. The pathological stages of resected specimens were T2/T3 in the majority of cases $(47 / 61,77.0 \%)$. Lymph node metastasis was detected in 45 patients $(73.7 \%)$.

Clinical findings of eligible patients at and after recurrence. Table II shows clinical findings at the detection of initial recurrence and treatment outcomes after recurrence. Recurrence was detected in 31 patients $(50.8 \%)$ less than 6 months after surgery. SCC values were higher than the standard value in 30 patients, while those of CYFRA were higher in 12 patients at recurrence. Recurrence was single in 32 patients $(52.4 \%)$ at initial recurrence and located in a lymph node in most of these cases (26/32 patients, $81.3 \%$ ). The remaining patients had multiple recurrent tumors at the detection of initial recurrence. The initial treatment against recurrent tumors was chemotherapy with/without radiotherapy in most patients (53/61 patients $86.9 \%)$. CR was achieved by 17 patients $(27.8 \%)$. The mean survival time after recurrence was 515.7 days (range $=71-1925$ days).

Prognostic factors in recurrent case. Table III shows the results of the univariate and multivariate analyses of prognostic factors in recurrent cases. Survival after the detection of initial recurrence (SAR) was compared according to different variables. In the univariate analysis, no significant differences were observed in differentiation, tumor size, pathological invasion depth, lymph node metastasis, lymphatic invasion, venous invasion, the value of SCC at the detection of initial recurrence, or CR to the initial treatment. On the other hand, the 2-year SAR of cases with single recurrence was significantly better than those with multiple recurrent tumors $(49.5 \%$ vs. $19.0 \%, p=0.015)$. The SAR of patients with high CYFRA values was significantly worse than that of cases with low CYFRA values $(8.3 \%$ vs. $45.3 \%, p<0.001)$. The SAR of patients who received CRT for recurrent tumors was significantly better than patients who received other treatments (49.9 vs. 27.6\%, $p=0.028$ ), and the SAR of patients who developed recurrence less than 6 months after surgery was significantly worse than those developing recurrence 6 months or more after surgery (22.1\% vs. $57.2 \%, p=0.032)$. A multivariable analysis was 
Table I. Background of eligible patients with postoperative recurrence of esophageal cancer $(n=61)$.

\begin{tabular}{|c|c|}
\hline Variable & Value \\
\hline \multicolumn{2}{|l|}{ Age, years } \\
\hline Mean \pm SD (range) & $65.4 \pm 7.9(48-83)$ \\
\hline \multicolumn{2}{|l|}{ Gender, n (\%) } \\
\hline Male & $47(77.0$ \\
\hline Female & $14(22.9 \%)$ \\
\hline \multicolumn{2}{|c|}{ Location of primary tumor, $\mathrm{n}(\%)$} \\
\hline $\mathrm{Ce}$ & $1(1.6 \%)$ \\
\hline Ut & $4(6.6 \%)$ \\
\hline Mt & $34(55.7 \%)$ \\
\hline $\mathrm{Lt}$ & $21(34.4 \%)$ \\
\hline $\mathrm{Ae}$ & $1(1.6 \%)$ \\
\hline \multicolumn{2}{|c|}{ Tumor differentiation, $\mathrm{n}(\%)$} \\
\hline Well & $11(18.0 \%)$ \\
\hline Moderate & $35(57.3 \%)$ \\
\hline Poor & $15(24.6 \%)$ \\
\hline \multicolumn{2}{|c|}{ Pathological invasion depth, n (\%) } \\
\hline $\mathrm{T} 1$ & $14(22.9 \%)$ \\
\hline $\mathrm{T} 2$ & $13(21.3 \%)$ \\
\hline $\mathrm{T} 3$ & $34(55.7 \%)$ \\
\hline \multicolumn{2}{|c|}{ Pathological lymph node metastasis, n (\%) } \\
\hline Positive & $45(73.7 \%)$ \\
\hline \multicolumn{2}{|c|}{ Lymphatic invasion, n (\%) } \\
\hline Positive & $33(54.1 \%)$ \\
\hline \multicolumn{2}{|l|}{ Venous invasion, $\mathrm{n}(\%)$} \\
\hline Positive & $24(39.3 \%)$ \\
\hline \multicolumn{2}{|c|}{ Neoadjuvant therapy, $\mathrm{n}(\%)$} \\
\hline FP & $55(9.8 \%)$ \\
\hline None & $6(91.1$ \\
\hline \multicolumn{2}{|c|}{ Pathological response to chemotherapy, n (\%) } \\
\hline Grade 0 & $2(3.2 \%)$ \\
\hline Grade 1a & $31(50.8 \%)$ \\
\hline Grade $1 \mathrm{~b}$ & $9(14.7 \%)$ \\
\hline Grade 2 & $2(3.2 \%)$ \\
\hline
\end{tabular}

Ce: Cervical esophagus; Ut: upper thoracic esophagus; Mt: middle thoracic esophagus; Lt: lower thoracic esophagus; Ae: abdominal esophagus; FP: 5-fluorouracil and cisplatin; SD: standard deviation.

performed on these significant variables, namely multiplicity of recurrence, CYFRA level, and the duration from surgery to recurrence, using Cox's proportional hazard model. Although a significant variable in univariate analysis, treatment of recurrence was excluded from this multivariate analysis because it strongly confounded multiplicity of recurrence. As a result, it was not possible to detect significant independent prognostic factors. However, single recurrence and low CYFRA values appeared to be good prognostic factors ( $p=0.065$ and $p=0.070$, respectively).

Evaluation of cases with single recurrence with small metastasis. Our present results on prognostic factors for recurrent cases showed that the prognosis of those with single recurrent tumor appeared to be good. A previous study
Table II. Clinical findings of eligible patients at and after recurrence of esophageal cancer $(n=61)$.

\begin{tabular}{|c|c|}
\hline Variable & Value \\
\hline \multicolumn{2}{|c|}{$\mathrm{SCC}$ at recurrence, $\mathrm{n}(\%)$} \\
\hline$<1.5 \mathrm{ng} / \mathrm{ml}$ & $31(50.8 \%)$ \\
\hline$\geq 1.5 \mathrm{ng} / \mathrm{ml}$ & $30(49.1 \%)$ \\
\hline \multicolumn{2}{|c|}{ CYFRA at recurrence, $\mathrm{n}(\%)$} \\
\hline$<3.5 \mathrm{ng} / \mathrm{ml}$ & $49(80.3 \%)$ \\
\hline$\geq 3.5 \mathrm{ng} / \mathrm{ml}$ & $12(19.6 \%)$ \\
\hline \multicolumn{2}{|c|}{ Location of recurrence, $\mathrm{n}(\%)$} \\
\hline \multicolumn{2}{|l|}{ Single } \\
\hline Local & $2(3.2 \%)$ \\
\hline Lymph node & $26(42.6 \%)$ \\
\hline \multicolumn{2}{|c|}{ Distant metastasis } \\
\hline Liver & $1(1.6 \%)$ \\
\hline Brain & $1(1.6 \%)$ \\
\hline Other & $2(3.2 \%)$ \\
\hline Multiple & $29(47.5 \%)$ \\
\hline \multicolumn{2}{|c|}{ Tumor diameter $(\mathrm{n}=80), \mathrm{mm}$} \\
\hline Mean \pm SD (range) & $14.4 \pm 9.8(3-63)$ \\
\hline \multicolumn{2}{|c|}{ Treatment for recurrence, $\mathrm{n}(\%)$} \\
\hline CRT & $29(47.5 \%)$ \\
\hline RT & $5(8.1 \%)$ \\
\hline Chemotherapy & $24(39.3 \%)$ \\
\hline Surgery & $1(1.6 \%)$ \\
\hline Other & $2(3.2 \%)$ \\
\hline $\begin{array}{l}\text { Complete response to } \\
\text { for recurrence, } \mathrm{n}(\%)\end{array}$ & $17(27.8 \%)$ \\
\hline \multicolumn{2}{|l|}{ Duration from surgery } \\
\hline Mean \pm SD (range) & $349.1 \pm 362.4(52-1791)$ \\
\hline \multicolumn{2}{|c|}{ Survival after recurrence, days } \\
\hline Mean \pm SD (range) & $515.7 \pm 406.3(71-1925)$ \\
\hline
\end{tabular}

SCC: Squamous cell carcinoma antige; CYFRA: cytokeratin 19 fragment; CRT: chemoradiotherapy; RT: radiotherapy; SD: standard deviation.

reported that small lymph node metastases are detectable using PET-CT (12). Based on our results and these findings, we investigated whether PET-CT contributes to improvements in the prognoses of patients with recurrence after curative surgery through the early detection of single small recurrent tumors. We analyzed 26 cases of single recurrence diagnosed using PET-CT. Table IV shows the characteristics of these cases. Recurrent regions were a lymph node in the majority of cases $(20 / 26,70.6 \%)$. PET-CT had the ability to reveal small tumors, the size of which was less than $10 \mathrm{~mm}$, at a high rate (in 11 patients, $42.3 \%$ ). Figure 1A and B show plain CT and PET-CT findings for a patient with a small metastasis. Although CT was unable to detect metastatic tumors, metabolic information on the uptake of FDG provided by PET-CT revealed these tumors. Sixteen patients received CRT, while the remaining patients undewent radiotherapy, chemotherapy, or gamma knife therapy. We divided these patients based on tumor size into 
Table III. Univariate and multivariate analyses of prognostic factors for patients with recurrent esophageal cancer.

\begin{tabular}{|c|c|c|c|c|c|c|c|}
\hline \multirow[b]{2}{*}{ Variable } & & \multirow[b]{2}{*}{$\mathrm{n}$} & \multicolumn{2}{|c|}{ Univariate } & \multicolumn{3}{|c|}{ Multivariate } \\
\hline & & & SAR $(\%)$ & $p$-Value & HR & $95 \% \mathrm{CI}$ & $p$-Value \\
\hline \multirow[t]{2}{*}{ Tumor differentiation } & Well/moderate & 46 & 38.0 & 0.961 & & & \\
\hline & Poor & 15 & 35.7 & & & & \\
\hline \multirow[t]{2}{*}{ Tumor size } & $\geq 50 \mathrm{~mm}$ & 19 & 33.3 & 0.834 & & & \\
\hline & $<50 \mathrm{~mm}$ & 41 & 39.3 & & & & \\
\hline \multirow[t]{2}{*}{ Pathological invasion depth } & $\mathrm{T} 1 / \mathrm{T} 2$ & 27 & 38.3 & 0.783 & & & \\
\hline & $\mathrm{T} 3$ & 34 & 36.4 & & & & \\
\hline \multirow{2}{*}{ Pathological lymph node metastasis } & Negative & 16 & 45.1 & 0.153 & & & \\
\hline & Positive & 45 & 32.4 & & & & \\
\hline \multirow{2}{*}{ Lymphatic invasion } & Negative & 28 & 36.0 & 0.957 & & & \\
\hline & Positive & 33 & 37.6 & & & & \\
\hline \multirow[t]{2}{*}{ Venous invasion } & Negative & 37 & 46.1 & 0.330 & & & \\
\hline & Positive & 24 & 23.1 & & & & \\
\hline \multirow[t]{2}{*}{ Multiplicity of recurrence } & Single & 37 & 49.5 & 0.015 & 0.534 & $0.268-1.042$ & 0.065 \\
\hline & Multiple & 24 & 19.0 & & 1.00 & & \\
\hline \multirow[t]{2}{*}{ SCC } & Low $(<1.5 \mathrm{ng} / \mathrm{ml})$ & 31 & 35.1 & 0.792 & & & \\
\hline & $\operatorname{High}(\geq 1.5 \mathrm{ng} / \mathrm{ml})$ & 30 & 38.5 & & & & \\
\hline \multirow[t]{2}{*}{ CYFRA } & Low $(<3.5 \mathrm{ng} / \mathrm{ml})$ & 49 & 45.3 & $<0.001$ & 0.476 & $0.222-1.066$ & 0.070 \\
\hline & High $(\geq 3.5 \mathrm{ng} / \mathrm{ml})$ & 12 & 8.3 & & 1.00 & & \\
\hline \multirow[t]{2}{*}{ Treatment for recurrence } & CRT & 29 & 49.9 & 0.028 & & & \\
\hline & Other & 32 & 27.6 & & & & \\
\hline \multirow[t]{2}{*}{ Response to treatment for recurrence } & $\mathrm{CR}$ & 17 & 49.4 & 0.164 & & & \\
\hline & Non-CR & 44 & 32.4 & & & & \\
\hline \multirow[t]{2}{*}{ Duration from surgery to recurrence } & $\geq 6$ Months & 30 & 57.2 & 0.032 & 0.797 & $0.364-1.608$ & 0.539 \\
\hline & $<6$ Months & 31 & 22.1 & & 1.00 & & \\
\hline
\end{tabular}

SAR: Two-year survival after recurrence; SCC: squamous cell carcinoma antigen; CYFRA: cytokeratin 19 fragment; CRT: chemoradiotherapy; CR: complete responce.

groups with tumor of less than $10 \mathrm{~mm}$ diameter and $10 \mathrm{~mm}$ or more, and evaluated survival curves (Figure 2). The results obtained showed that the prognoses of the 11 cases small tumors were significantly better than the 15 non-cases with larger tumors $(p=0.045)$.

Efficacy of PET-CT in the detection of recurrent tumors outside the body trunk. Three patients with initial recurrent tumors outside the body trunk, two with brain metastasis and one with elbow joint metastasis, were diagnosed using PETCT. Figure 1C-F shows plain CT and PET-CT results in 2 out of these patients. Although one patient with brain metastasis and the patient with metastasis of the elbow joint exhibited some symptoms indicating the existence of these recurrent tumors, the other patient without any symptoms was incidentally diagnosed with brain metastasis. This patient was a 52-year-old woman who underwent curative subtotal esophagectomy with lymphadenectomy after neoadjuvant chemotherapy. Fifteen months after surgery, brain metastasis was detected using PET-CT (Figure 1E and F). Gamma knife therapy (total $60 \mathrm{~Gy}$ ) was performed on this tumor, and CR was achieved. The patient is currently alive 54 months after surgery. Therefore, PET-CT may
Table IV. Clinical findings of single recurrent cases $(n=26)$ with small tumors.

\begin{tabular}{lc}
\hline Variable & Value \\
\hline Recurrence, $\mathrm{n}(\%)$ & \\
$\quad$ Local & $2(7.6 \%)$ \\
Lymph node metastasis & $20(76.9 \%)$ \\
$\quad$ Distant metastasis & $4(15.3 \%)$ \\
Tumor size, mm & \\
Mean \pm SD (range) & $14.8 \pm 13.5(4.9-63.0)$ \\
$\geq 10$ & $15(57.6 \%)$ \\
$<10$ & $11(42.3 \%)$ \\
Treatment for recurrent lesions, $\mathrm{n}(\%)$ & $16(61.5 \%)$ \\
CRT & $4(15.3 \%)$ \\
RT & $4(15.3 \%)$ \\
Chemotherapy & $1(3.8 \%)$ \\
Gamma knife & $8(30.7 \%)$ \\
Complete response, $\mathrm{n}(\%)$ & \\
\hline
\end{tabular}

CRT: Chemoradiotherapy; RT: radiotherapy; SD: standard deviation.

contribute to the early detection of recurrent tumors outside the body trunk and lead to long-term survival after recurrence. 

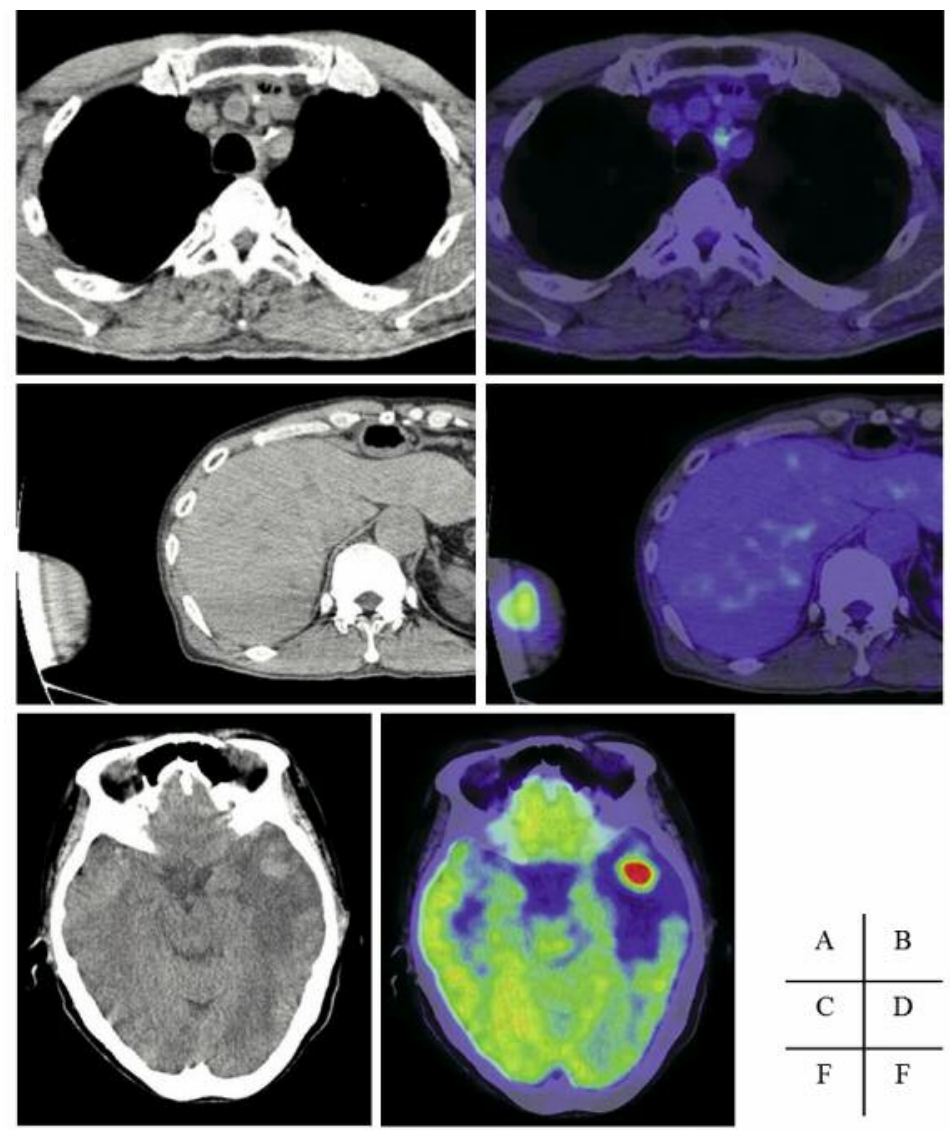

Figure 1. Positron-emission tomography with 2-deoxy-2-[fluorine-18]fluoro-D-glucose integrated with computed tomography (PET-CT) findings of three patients with postoperative recurrence of esophageal cancer. A, B: This patient was diagnosed with postoperative recurrence using PET-CT 26 months after surgery. Although the metastasis was not detectable by plain CT, it was identified using PET-CT. C, D: This patient was diagnosed with elbow joint metastasis using PET-CT 59 months after surgery. A whole-body scan using PET-CT contributed to the detection of the recurrent tumor outside the body trunk. E, F: This patient, who did not have any symptoms at that time, was incidentally diagnosed with brain metastasis using PET-CT 15 months after surgery. Gamma knife therapy was performed on this tumor, and complete response was achieved. This patient is still alive 54 months after surgery.

\section{Discussion}

The development of effective multimodal therapies for EC has recently improved the prognosis of patients with EC. For example, neoadjuvant chemotherapy before curative surgery has been shown to improve the prognosis of patients with EC (13), and the clinical outcomes of definitive CRT are now similar to those of curative surgery (14). Furthermore, a new chemotherapeutic regimen involving 5-fluorouracil, cisplatin and docetaxel, and a new method of radiotherapy called intensity-modulated radiotherapy, are receiving increasing attention as more effective therapies against EC $(15,16)$. These advances in therapies directed at EC also improve the prognosis of patients with postoperative recurrence of EC. A previous study reported that salvage radiotherapy or CRT for locoregional recurrence after surgery for EC was safe and effective (17). The effectiveness of multimodal therapies involving chemotherapy, salvage surgery, and salvage CRT against recurrent tumors has already been demonstrated $(18,19)$. Concurrent threedimensional conformal radiotherapy, which is similar to intensity-modulated radiotherapy, and chemotherapy may increase local tumor control, reduce the rate of distant metastasis, and increase long-term survival rates $(20,21)$. These findings suggest that the postoperative recurrence of $\mathrm{EC}$ is no longer as incurable as it once was. Therefore, recurrent tumors need to be detected as soon as possible and treated effectively.

Previous studies investigated the utility of FDG-PET in EC (22). PET-CT is widely performed as an imaging 


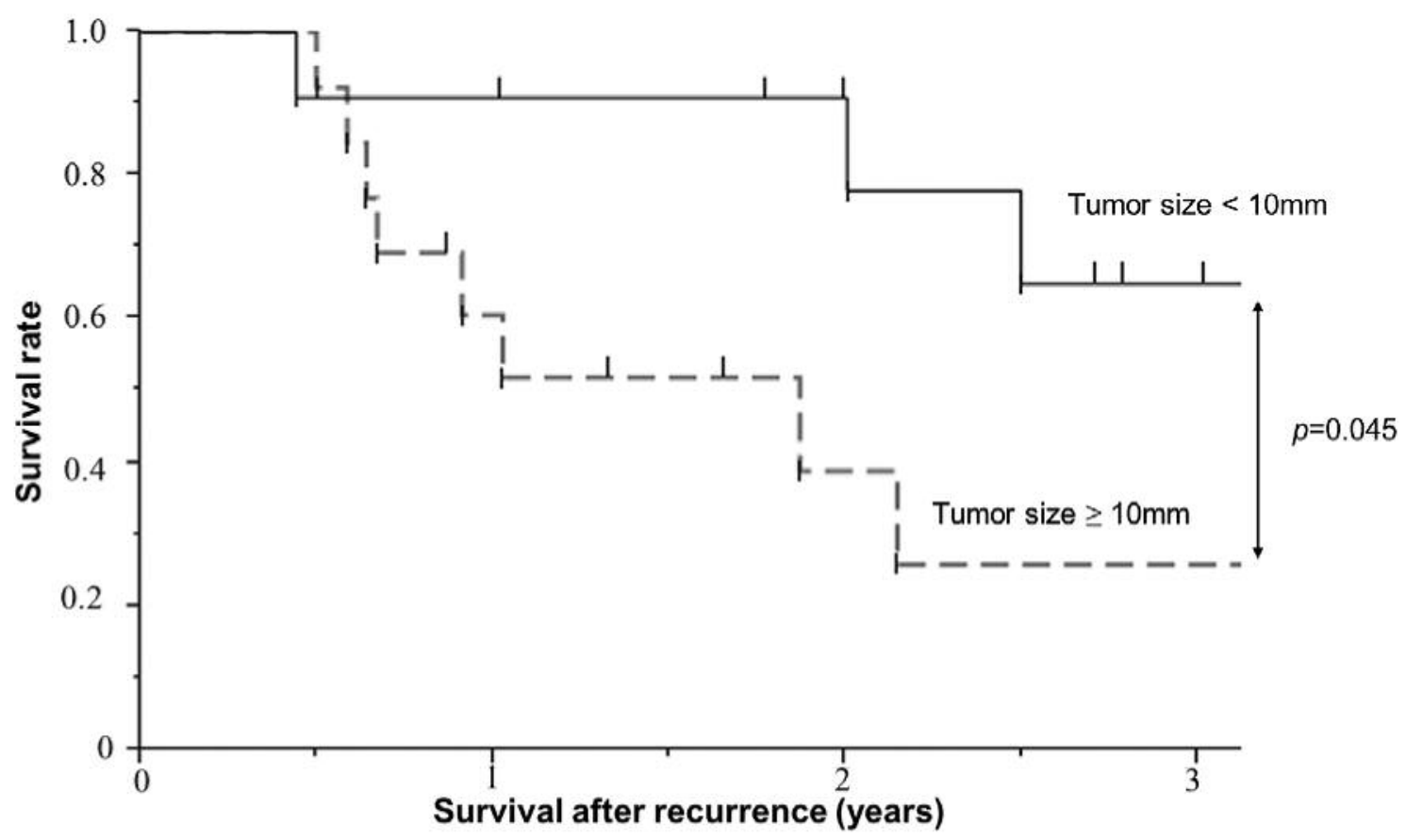

Figure 2. Long-term outcomes of patients with single recurrent tumors according to tumor diameter.

examination for the staging and detection of recurrent tumors. However, its utility in postoperative follow-up has not yet been established. The diagnostic superiority of metabolism-based methods, such as FDG-PET, may be most pronounced under conditions in which the non-specific sequelae of surgery, radiotherapy, or chemotherapy render conventional, anatomy-based modalities less accurate. On the other hand, CT has been widely used as an imaging examination in regular follow-up of patients after curative resection of EC. However, CT often has difficulties in detecting a postoperative recurrent lesion because it identifies abnormal lesions based on normal anatomy. For example, it is often challenging to establish whether lymph nodes less than $10 \mathrm{~mm}$ in size are metastatic using CT. In contrast, PET-CT often identifies their status because it provides metabolic information. In a previous study, PET-CT was shown to have the ability to detect small lymph node metastases with a minimum diameter of $0.9 \mathrm{~mm}$ (12). Moreover, PET and CT are regarded as reliable imaging modalities with high sensitivity and moderate specificity for detecting recurrent EC after treatments with curative intent (23). In the systematic review and meta-analysis by Goense et al., the sensitivity of PET-CT ranged between $89 \%$ and $100 \%$ and the specificity between $55 \%$ and $94 \%$ for the detection of recurrent EC (23). On the other hand, previous studies reported that the sensitivity of contrast-enhanced CT ranged between $65 \%$ and $89 \%$ and specificity between $79 \%$ and $91.2 \%$ for the detection of recurrent $\operatorname{EC}(8,24)$. Although the lower specificity of PET-CT is a limitation for patients with EC, its higher sensitivity may contribute to the early start of treatments for recurrent tumors, which may, in turn, improve the prognosis of patients with recurrent EC. Therefore, PET-CT needs to be considered for use in the postoperative follow-up of patients with EC.

The evaluation of responses to treatments for recurrent tumors has also been performed using PET-CT at our Division since January 2008. Although it remains controversial whether PET-CT is appropriate as an imaging modality for evaluating responses to cancer treatments, its usefulness was previously demonstrated. It is impossible to evaluate viable tumor tissues using the other imaging modalities, CT and magnetic resonance imaging, whereas PET-CT has the ability to evaluate cancer function on the basis of information on glucose metabolism. Comparisons between cancer metabolism revealed by PET-CT before and after treatments enables evaluation of responses to treatments $(6,24,25)$. Previous studies reported that decreases of standardized uptake value in tumors evaluated by PET-CT after preoperative chemoradiotherapy were associated with histopathological tumor responses $(26,27)$. Moreover, PETCT performed after CRT predicted the prognoses of patients with primary or postoperative recurrent EC $(28,29)$. These 
findings suggest that PET-CT is as effective as other imaging modalities in the evaluation of responses to cancer treatments.

Although PET-CT needs to be used in the follow-up of postoperative $\mathrm{EC}$ as described above, the frequency at which it needs to be performed or whether CT needs to be used concurrently has not yet been established. To the best of our knowledge, this is the first study to investigate the clinical outcomes of patients with EC, followed-up using PET-CT only. We consider PET-CT to have two advantages over CT in the postoperative follow-up of patients with EC. The first advantage is that PET-CT has the ability to reveal whether small nodes are metastatic through the uptake of FDG, which indicates cancer metabolism. The second advantage is that PET-CT routinely scans the whole body. In the present study, PET-CT revealed small tumors, the diameters of which were less than $10 \mathrm{~mm}$, as well as recurrent tumors outside the body trunk, which are not detectable by CT. The patient with brain metastasis, which was incidentally diagnosed using regular follow-up PET-CT, has already survived for more than 3 years since this recurrence. Furthermore, patients with single recurrent tumors of less than $10 \mathrm{~mm}$ in size survived for a significantly longer time than those with tumors that were $10 \mathrm{~mm}$ or more in size. We consider that these results support the utility of this modality. A limitation of our study is the relatively small sample size, which may limit the statistical power. Furthermore, it was not possible to perform comparisons of clinical outcomes between followup by CT and that by PET-CT. More patients will be accumulated and a prospective study planned.

In conclusion, we analyzed the clinical outcomes of patients who developed postoperative recurrence and were followed-up using PET-CT. PET-CT may contribute to the early detection of small recurrent tumors and searches outside the body trunk. The method of this follow-up needs to be considered for patients after EC surgery.

\section{References}

1 Ferlay J, Soerjomataram I, Dikshit R, Eser S, Mathers C, Rebelo M, Parkin DM, Forman D and Bray F: Cancer incidence and mortality worldwide: sources, methods and major patterns in GLOBOCAN 2012. Int J Cancer 136: E359-386, 2015.

2 Tachimori Y, Ozawa S, Numasaki H, Fujishiro M, Matsubara H, Oyama T, Shinoda M, Toh Y, Udagawa $\mathrm{H}$ and Uno $\mathrm{T}$ : Comprehensive Registry of Esophageal Cancer in Japan, 2008. Esophagus 12: 130-157, 2015.

3 Tachimori Y, Ozawa S, Numasaki H, Fujishiro M, Matsubara H, Oyama T, Shinoda M, Toh Y, Udagawa $\mathrm{H}$ and Uno $\mathrm{T}$ : Comprehensive registry of esophageal cancer in Japan, 2007 Esophagus 12: 101-129, 2015.

4 Kato T, Harano M, Idani H, Choda Y, Tokumoto N, Kanazawa T, Matsukawa H, Ojima Y, Shiozaki S, Okajima M, Ninomiya M, Matsuura K, Hirokawa Y and Ohno S: An examination of the utility of high-precise radiation therapies for the recurrence of postoperative esophageal cancer. Gan to kagaku ryoho 41: 23932395, 2014. (in Japanese).
5 Takemura M, Kaibe N, Takii M, Yoshida K, Niwa H, Oshima T, Kikuchi S and Sasako M: Treatment outcomes of patients with cervical lymph node recurrence after esophagectomy for esophageal cancer. Gan to kagaku ryoho Cancer \& chemotherapy 41: 2010-2012, 2014. (in Japanese).

6 Kato $\mathrm{H}$ and Nakajima M: The efficacy of FDG-PET for the management of esophageal cancer: review article. Annals of Thoracic and Cardiovascular Surgery 18: 412-419, 2012.

7 Karashima R, Watanabe M, Imamura Y, Ida S, Baba Y, Iwagami $\mathrm{S}$, Miyamoto $\mathrm{Y}$, Sakamoto $\mathrm{Y}$, Yoshida $\mathrm{N}$ and Baba $\mathrm{H}$ : Advantages of FDG-PET/CT over CT alone in the preoperative assessment of lymph node metastasis in patients with esophageal cancer. Surg Today 45: 471-477, 2015.

8 Kato H, Miyazaki T, Nakajima M, Fukuchi M, Manda R and Kuwano H: Value of positron emission tomography in the diagnosis of recurrent oesophageal carcinoma. Br J Surg 91: 1004-1009, 2004.

9 Kuwano H, Nishimura Y, Oyama T, Kato H, Kitagawa Y, Kusano M, Shimada H, Takiuchi H, Toh Y, Doki Y, Naomoto Y, Matsubara $\mathrm{H}$, Miyazaki $\mathrm{T}$, Muto $\mathrm{M}$ and Yanagisawa $\mathrm{A}$ : Guidelines for Diagnosis and Treatment of Carcinoma of the Esophagus April 2012 edited by the Japan Esophageal Society. Esophagus 12: 1-30, 2015.

10 Fujita H: Japanese Classification of Esophageal Cancer, Tenth Edition: Part I. Esophagus 6: 1-25, 2009.

11 Eisenhauer EA, Therasse P, Bogaerts J, Schwartz LH, Sargent D, Ford R, Dancey J, Arbuck S, Gwyther S, Mooney M, Rubinstein L, Shankar L, Dodd L, Kaplan R, Lacombe D and Verweij J: New response evaluation criteria in solid tumours: revised RECIST guideline (version 1.1). European journal of cancer (Oxford, England: 1990) 45: 228-247, 2009.

12 Yamada H, Hosokawa M, Itoh K, Takenouchi T, Kinoshita Y, Kikkawa T, Sakashita K, Uemura S, Nishida Y, Kusumi T and Sasaki S: Diagnostic value of (1)(8)F-FDG PET/CT for lymph node metastasis of esophageal squamous cell carcinoma. Surg Today 44: 1258-1265, 2014.

13 Ando N, Kato H, Igaki H, Shinoda M, Ozawa S, Shimizu H, Nakamura T, Yabusaki H, Aoyama N, Kurita A, Ikeda K, Kanda T, Tsujinaka T, Nakamura $\mathrm{K}$ and Fukuda $\mathrm{H}$ : $\mathrm{A}$ randomized trial comparing postoperative adjuvant chemotherapy with cisplatin and 5-fluorouracil versus preoperative chemotherapy for localized advanced squamous cell carcinoma of the thoracic esophagus (JCOG9907). Ann Surg Oncol 19: 68-74, 2012.

14 Kato H, Sato A, Fukuda H, Kagami Y, Udagawa H, Togo A, Ando N, Tanaka O, Shinoda M, Yamana H and Ishikura S: A phase II trial of chemoradiotherapy for stage I esophageal squamous cell carcinoma: Japan Clinical Oncology Group Study (JCOG9708). Jpn J Clin Oncol 39: 638-643, 2009.

15 Lin SH, Wang L, Myles B, Thall PF, Hofstetter WL, Swisher SG, Ajani JA, Cox JD, Komaki R and Liao Z: Propensity scorebased comparison of long-term outcomes with 3-dimensional conformal radiotherapy $v s$. intensity-modulated radiotherapy for esophageal cancer. Int J Radiat Oncol Biol Phys 84: 1078-1085, 2012.

16 Tanaka Y, Yoshida K, Yamada A, Tanahashi T, Okumura N, Matsuhashi N, Yamaguchi K and Miyazaki T: Phase II trial of biweekly docetaxel, cisplatin, and 5-fluorouracil chemotherapy for advanced esophageal squamous cell carcinoma. Cancer Chemother Pharmacol 77: 1143-1152, 2016. 
17 Kobayashi R, Yamashita H, Okuma K, Shiraishi K, Ohtomo K and Nakagawa $\mathrm{K}$ : Salvage radiation therapy and chemoradiation therapy for postoperative locoregional recurrence of esophageal cancer. Dis Esophagus 27: 72-78, 2014.

18 Iitaka D, Shiozaki A, Fujiwara H, Ichikawa D, Okamoto K, Komatsu S, Murayama Y, Ikoma H, Kuriu Y, Nakanishi M, Ochiai T, Kokuba Y, Sonoyama T and Otsuji E: Case involving long-term survival after esophageal cancer with liver and lung metastases treated by multidisciplinary therapy: report of a case. Surg Today 43: 556-561, 2013.

19 Watanabe M, Mine S, Yamada K, Shigaki H, Baba Y, Yoshida N, Kajiyama K, Yamamoto N, Sano T and Baba H: Outcomes of lymphadenectomy for lymph node recurrence after esophagectomy or definitive chemoradiotherapy for squamous cell carcinoma of the esophagus. Gen Thorac Cardiovasc Surg 62: 685-692, 2014

20 Ma DY, Tan BX, Liu M, Li XF, Zhou YQ and Lu Y: Concurrent three-dimensional conformal radiotherapy and chemotherapy for postoperative recurrence of mediastinal lymph node metastases in patients with esophageal squamous cell carcinoma: a phase 2 single-institution study. Radiation oncology (London, England) 9: 28,2014

21 Bao Y, Liu S, Zhou Q, Cai P, Anfossi S, Li Q, Hu Y, Liu M, Fu J, Rong T, Li Q and Liu H: Three-dimensional conformal radiotherapy with concurrent chemotherapy for postoperative recurrence of esophageal squamous cell carcinoma: clinical efficacy and failure pattern. Radiation oncology (London, England) 8: 241, 2013.

22 Farwell MD, Pryma DA and Mankoff DA: PET/CT imaging in cancer: current applications and future directions. Cancer 120: 3433-3445, 2014

23 Goense L, van Rossum PS, Reitsma JB, Lam MG, Meijer GJ, van Vulpen M, Ruurda JP and van Hillegersberg R: Diagnostic performance of (1)(8)F-FDG PET and PET/CT for the detection of recurrent esophageal cancer after treatment with curative intent: a systematic review and meta-analysisysis. J Nucl Med 56: 995-1002, 2015.

24 Teyton P, Metges JP, Atmani A, Jestin-Le Tallec V, Volant A, Visvikis D, Bail JP, Pradier O, Lozac'h P and Cheze Le Rest C: Use of positron emission tomography in surgery follow-up of esophageal cancer. J Gastrointest Surg 13: 451-458, 2009.
25 Kato H, Kuwano H, Nakajima M, Miyazaki T, Yoshikawa M, Masuda N, Fukuchi M, Manda R, Tsukada K, Oriuchi N and Endo K: Usefulness of positron emission tomography for assessing the response of neoadjuvant chemoradiotherapy in patients with esophageal cancer. American journal of surgery 184: 279-283, 2002.

26 van Heijl M, Omloo JM, van Berge Henegouwen MI, Hoekstra OS, Boellaard R, Bossuyt PM, Busch OR, Tilanus HW, Hulshof MC, van der Gaast A, Nieuwenhuijzen GA, Bonenkamp HJ, Plukker JT, Cuesta MA, Ten Kate FJ, Pruim J, van Dekken H, Bergman JJ, Sloof GW and van Lanschot JJ: Fluorodeoxyglucose positron emission tomography for evaluating early response during neoadjuvant chemoradiotherapy in patients with potentially curable esophageal cancer. Ann Surg 253: 56-63, 2011.

27 Vera P, Dubray B, Palie O, Buvat I, Hapdey S, Modzelewski R, Benyoucef A, Rousseau C, Meyer ME, Bardet S, Gardin I, Fiore FD and Michel P: Monitoring tumour response during chemoradiotherapy: a parametric method using FDG-PET/CT images in patients with oesophageal cancer. EJNMMI Res 4: 12, 2014.

28 Jingu K, Kaneta T, Nemoto K, Takeda K, Ogawa Y, Ariga H, Koto M, Sakayauchi T, Takai Y, Takahashi S and Yamada S: (18)F-fluorodeoxyglucose positron emission tomography immediately after chemoradiotherapy predicts prognosis in patients with locoregional postoperative recurrent esophageal cancer. Int J Clin Oncol 15: 184-190, 2010.

29 Atsumi K, Nakamura K, Abe K, Hirakawa M, Shioyama Y, Sasaki T, Baba S, Isoda T, Ohga S, Yoshitake T, Shinoto M, Asai $\mathrm{K}$ and Honda $\mathrm{H}$ : Prediction of outcome with FDG-PET in definitive chemoradiotherapy for esophageal cancer. J Radiat Res 54: 890-898, 2013. 